\title{
Sepsis in the Emergency Department - Part 1: Definitions and Outcomes
}

\section{Authors:}

1. Stephen Macdonald BSc MBChB FRCP FACEM. Centre for Clinical Research in Emergency Medicine, Harry Perkins Institute of Medical Research, Perth, WA, Australia; Department of Emergency Medicine, Royal Perth Hospital, Perth WA, Australia; Division of Emergency Medicine, University of Western Australia, Perth, WA, Australia. Email stephen.macdonald@uwa.edu.au

2. Julian Williams MBBS, FACEM, Department of Emergency Medicine, Royal Brisbane and Women's Hospital, Brisbane, QLD, Australia; Faculty of Medicine, University of Queensland, Brisbane, QLD, Australia. Email: Julian.williams@health.qld.gov.au

3. Amith Shetty MBBS FACEM. Department of Emergency Medicine, Westmead Hospital, Sydney, NSW, Australia; Centre for Research in Critical Infection, Westmead Millennium Institute, Sydney, NSW, Australia. Email amith.shetty@health.nsw.gov.au

4. Rinaldo Bellomo, MD FRACP FCICM. Department of Intensive Care, Austin Hospital, Melbourne, VIC, Australia; School of Medicine, University of Melbourne, Melbourne, VIC, Australia. Email: Rinaldo.bellomo@austin.org.au

5. Simon Finfer MBBS FRCP FRCA FCICM FAHMS MD. The George Institute for Global Health, Sydney, University of New South Wales, NSW, Australia; Department of Intensive Care, Royal North Shore Hospital, Sydney, NSW, Australia; Email: sfinfer@georgeinstitute.org.au

This is the author manuscript accepted for publication and has undergone full peer review but has not been through the copyediting, typesetting, pagination and proofreading process, which may lead to differences between this version and the Version of Record. Please cite this article as doi: 10.1111/1742-6723.12886

This article is protected by copyright. All rights reserved. 
6. Nathan Shapiro MD MPH. Department of Emergency Medicine, Beth Israel Deaconess Medical Centre, Boston, MA, USA; Harvard Medical School, Boston, MA, USA. Email: nshapiro@bidmc.harvard.edu

7. Gerben Keijzers MSc (Biomed Health Sci) MBBS FACEM PhD.

Department of Emergency Medicine, Gold Coast University Hospital, Gold Coast, QLD, Australia and School of Medicine, Bond University, Gold Coast, QLD, Australia and School of Medicine, Griffith University, Gold Coast, QLD, Australia. E-mail: Gerben.Keijzers@health.qld.gov.au

All authors contributed equally to the submitted work

\section{Corresponding Author:}

Stephen Macdonald

Centre for Clinical Research in Emergency Medicine

Harry Perkins Institute of Medical Research

Royal Perth Hospital

GPO Box 2213

Perth, WA

Australia

T +61 892248458

E Stephen.macdonald@uwa.edu.au

\section{Conflict of Interest statement}

SM and GK are section editors for Emergency Medicine Australasia

This article is protected by copyright. All rights reserved. 


\section{Key Points}

- Sepsis is defined as acute organ dysfunction caused by infection

- Sepsis remains a clinical diagnosis, and vigilance is required to ensure prompt recognition and treatment

- Sepsis incidence is increasing, affecting particularly elderly patients with comorbidities

- Although mortality is falling, there is a substantial burden of morbidity among sepsis survivors

\section{Overview}

This is the first of a three-part mini-series on recent developments and future directions in sepsis. There has been substantial evolution in understanding of the epidemiology, clinical manifestations and pathogenic mechanisms of this important condition. While aimed primarily at an Emergency Medicine audience, this series should also be a useful summary for other clinicians and researchers. This paper will focus upon definitions and outcomes, while subsequent articles will address advances in diagnosis and management.

\section{Background and Historical Context}

Although first described in antiquity (the term 'sepsis' derives from the Greek word for decomposition), it wasn't until the $19^{\text {th }}$ century that the contemporary understanding of transmissible infectious disease began to evolve ${ }^{1}$. Major milestones were development of surgical asepsis and techniques for bacterial culture and classification. The antibiotic era commenced in the early decades of the $20^{\text {th }}$ century. Subsequent research determined the pivotal role bacterial toxins in disease pathogenesis, while the discovery of cytokines and role of the coagulation cascade in inflammation led to appreciation of sepsis as a 
dysregulated acute inflammatory condition, resulting in the various clinical manifestations of organ failure and shock. Sepsis is the principal cause of death resulting from infection.

\section{Epidemiology}

Sepsis is a major cause of morbidity and mortality worldwide. Contributing factors are an ageing population, increasing prevalence of chronic diseases, immunosuppression (both disease and therapy related), invasive medical procedures and antimicrobial resistance ${ }^{2}$. In Australia and New Zealand, the annual population incidence of sepsis treated in an Intensive Care Unit (ICU) has been estimated at $0.77 / 1000$, approximately 18,000 cases per year ${ }^{3}$. Analysis of routinely collected data from Australian ICUs indicates the incidence of sepsis has been increasing over time ${ }^{4}$.

Quantification of sepsis incidence and outcome using ICU datasets leverages the convenience of routinely collected data. However the majority of sepsis patients are admitted to general wards, including those who have limitations of care on the basis of advanced age, comorbidity or dependence ${ }^{5}$. Hospital administrative discharge coding has also been used extensively to quantify sepsis incidence and mortality. Limitations of this approach include lack of sensitivity and potential for other imperatives such as funding to influence codes recorded 6 . Specific diagnostic codes for sepsis (ICD-9 995.92/ICD-10 R65.20) or septic shock (ICD-9 785.52/ICD-10 R65.21) are often omitted from discharge summaries which list only the underlying source of infection 7 . Accurate measurement of sepsis rates in the ED can be labour-intensive and complicated by the fact that ED diagnoses are often necessarily presumptive ${ }^{8}$. The absence of a tissue diagnosis or a reliable diagnostic marker, a lack of settled diagnostic criteria, and a diverse array of measurement methods result in significant variation in reported sepsis incidence and outcomes ${ }^{9}$. This has implications for clinical resource allocation, policymaking, and research. 


\section{Evolution of sepsis definitions}

Roger Bone and colleagues first proposed a framework for sepsis classification in 198910, which was further refined through a consensus conference process in 199111. The resulting definition ('Sepsis-1') was based on the concept of the systemic inflammatory response syndrome (SIRS), where the host response to infection was characterised by physiological derangements in body temperature, heart and respiratory rates, and peripheral leucocyte count. Sepsis was defined as SIRS due to a suspected or proven infection, while severe sepsis described patients with consequent acute organ dysfunction. The most severe manifestation, septic shock, was defined as acute circulatory failure, characterised by persistent arterial hypotension, i.e. systolic blood pressure (SBP) $<90 \mathrm{mmHg}$ or mean arterial pressure (MAP) $<65 \mathrm{mmHg}$ or a decrease in SBP $>40 \mathrm{mmHg}$ from baseline or the need for vasopressor agents to maintain SBP or MAP above these threshold levels, despite adequate fluid resuscitation and unexplained by other causes. However, this approach to the definition of septic shock focussed the attention of clinicians on blood pressure rather than other important features of hypoperfusion.

A 2001 consensus statement on definitions (Sepsis-2) emphasized the importance of acute organ dysfunction as a trigger for early resuscitative interventions ${ }^{12}$. Sepsis-2 placed substantial weight upon clinical judgment of an infectious aetiology, along with a range of inflammatory and/or organ failure parameters as well as the established SIRS components. This prioritised practical clinical applicability; however, a lack of standardization was problematic for characterisation of patients in research studies.

SIRS attracted criticism for lack of specificity (e.g. a young patient with fever and tachycardia in the context of a viral respiratory infection was determined to have 'sepsis') as well as imperfect sensitivity. One study found $12 \%$ of ICU patients with infection and organ dysfunction did not have SIRS ${ }^{13}$. Partly in response to

This article is protected by copyright. All rights reserved. 
these shortcomings, in 2016 an international collaboration of critical care physicians proposed a revised definition (Sepsis-3) ${ }^{14}$. As well as removing SIRS as a requirement for diagnosis, the definition excludes infection with features of an inflammatory response but without associated organ dysfunction. The Sepsis3 criteria now define sepsis as an infection-related acute increase of 2 or more points from baseline in the Sequential Organ Failure Assessment (SOFA) score ${ }^{15}$ (Table 1). The updated definition of septic shock stipulates infection associated with persistent hypotension (without specifying blood pressure thresholds) requiring vasopressors to maintain adequate tissue perfusion, along with a blood lactate $>2 \mathrm{mmol} / \mathrm{L}$. A schematic summary of the 2001 (Sepsis-2) and 2016 (Sepsis-3) definitions is shown in Figure 1.

\section{Sepsis recognition in the ED}

Sepsis is a clinical syndrome with no tissue diagnostic or reliable serological test. Sepsis often presents insidiously, and the clinical features can be heterogeneous and non-specific. A number of guidelines have been developed with the aim of identifying patients with sepsis promptly. Typically, these are embedded within treatment pathways, incorporating tests for organ dysfunction, collection of culture specimens, administration of an intravenous fluid bolus, broad-spectrum antibiotics and ongoing monitoring. However, the ability to differentiate sepsis from uncomplicated infection is variable ${ }^{16}$.

Despite removal of SIRS from the sepsis definition, this remains a clinically useful tool. In a large Australian study of patients admitted from the ED with infection, the presence of SIRS was associated with increased risk of organ dysfunction ${ }^{17}$. SIRS also conferred increased mortality risk with infection even in the absence of organ failure. However, it is important to recognise sepsis may be present in the absence of SIRS. Attention to predisposing risk factors (e.g. immunosuppression, recent hospitalisation) is an important element. This is a feature of the ED Sepsis pathways produced by the NSW Clinical Excellence 
Commission [http://www.cec.health.nsw.gov.au/patient-safety-programs/adultpatient-safety/sepsis-kills].

The relationship between infection and organ dysfunction is dynamic, and absence of organ failure at first assessment still demands vigilance for its later development. These concepts are important, since an overly inclusive approach leads to inappropriate use of broad-spectrum antibiotics, potentially contributing to the growing problem of antimicrobial resistance ${ }^{18}$. Conversely limited ongoing assessment can lead to unrecognised deterioration without an appropriate response.

The question of how to optimally identify sepsis in the ED remains unresolved. The Surviving Sepsis Campaign recommends patients be screened for 'symptoms and signs of infection', and where this is suspected, undergo prompt laboratory testing for infection-related organ dysfunction, including bedside testing for lactate ${ }^{19}$. Increased serum lactate is known to be associated with worse outcome in sepsis ${ }^{20}$. Patients identified to be at higher risk should undergo rapid diagnostic workup and receive treatment according to standard sepsis resuscitation bundles.

Sepsis-3 has made the presence of infection-induced organ dysfunction (defined using the SOFA score) the sole criterion for diagnosis. The SOFA score, however, dates from 1996, includes reference to rarely used drugs such as dopamine and dobutamine, and requires recalibration ${ }^{17}$. Because the SOFA score is infrequently used outside the ICU, the Sepsis-3 authors identified three variables respiratory rate $\geq 22 / \mathrm{min}$, systolic blood pressure $<100 \mathrm{mmHg}$ and altered mentation - with the presence of 2 of these 3 variables conferring a $10 \%$ inhospital mortality risk ${ }^{21}$. This so-called 'quick-SOFA' score (qSOFA) was suggested for use at the bedside in the ward or ED as a 'screening' test for identifying patients with possible sepsis who are at higher risk. Importantly its predictive value was not specifically assessed in ED patients, and sensitivity for

This article is protected by copyright. All rights reserved. 
detecting adverse outcomes outside the ICU has been found to be limited17,22,23. Thus, it cannot be recommended for this purpose. Rather qSOFA should be considered a severity assessment tool to identify those with infection at particularly high risk of deterioration, and prompt rapid evaluation and expedited care ${ }^{24}$.

\section{Risk stratification of suspected sepsis in the ED}

The vast majority of patients presenting to the ED with features of infection have an uncomplicated clinical course and will be suitable for treatment on a general ward or in the community. Differentiating sepsis from uncomplicated infection is important to ensure rapid treatment for those who require it, balanced against the harms of overtreatment for those who do not.

Risk stratification tools may be specific to a particular infection, such as the SMARTCOP 25 and CORB $^{26}$ scores for community acquired pneumonia. In contrast, the Acute Physiology and Chronic health Evaluation (APACHE) scoring system was developed for risk stratification of all patients admitted to ICUs, however it is impractical to apply it in the ED 27 . The Mortality in Emergency Department Sepsis (MEDS) score incorporates a range of clinical variables to predict mortality risk among patients with suspected infection in the ED who were identified pragmatically by a clinical decision to order blood cultures ${ }^{28}$ (Table 2). The SOFA score is objective, and is based upon readily available clinical and laboratory parameters, but takes no account of patient predisposing factors such as age or comorbidity. A recently published study in a cohort of 8,871 consecutive patients admitted with infection at a single Australian teaching hospital found good predictive performance of both MEDS and SOFA applied in the $\mathrm{ED}^{29}$.

An important factor driving illness severity is the virulence of the infecting organism. The "Predisposition, Insult, Response, Organ failure" (PIRO) score was 
proposed as a staging system for sepsis ${ }^{30}$. Analogous to the Tumour Nodes Metastases (TNM) system for cancer, it was hoped PIRO would allow better characterization of sepsis phenotypes for clinical trial recruitment. An obvious limitation for use of the PIRO system in the ED is the lack of knowledge of the infecting organism in most instances. Howell and colleagues therefore developed a PIRO model based upon the likely clinical source of infection (in lieu of the 'I' component) ${ }^{31}$. This PIRO model is more complex than the MEDS and SOFA scores, but has been demonstrated to be predictive of mortality and need for ICU admission among patients with sepsis in the ED ${ }^{32}$. However, PIRO has not been widely adopted.

In the future, the advent of electronic health records may allow for routinely recorded clinical data to trigger early warning systems built on increasingly complex 'machine learning' based algorithms ${ }^{33}$. However, at present sepsis remains a clinical diagnosis, informed by supporting evidence of infection and organ dysfunction. There is no single diagnostic test, and recognition of this lifethreatening illness in the ED requires a high level of vigilance and suspicion. A systematic approach to assessment of the patient presenting with suggestive features is required. Diagnostic criteria will continue to evolve in the light of shifting epidemiologic trends and rapid changes in understanding of pathogenic mechanisms of organ failure and shock. There is a tension between operational and research imperatives in this regard. Risk stratification remains the key to balancing identification and rapid treatment of patients at high risk while minimising harms of over-treatment in patients with uncomplicated infections.

\section{Outcomes}

\section{Mortality}

The mortality of patients with sepsis varies according to definitions and subpopulations. Studies of hospitalized patients with sepsis identified by means 
of coding-based approaches report mortality rates that vary according to the codes used ${ }^{34}$. Case fatality rates varying between $15 \%$ and $45 \%$ are reported 35 . Similarly, studies of ICU patients report different mortality rates according to the approach used to identify the presence of sepsis and, for patients involved in sepsis trials, according to the inclusion and exclusion criteria. Accordingly, comparisons between different studies can be misleading.

The Australian and New Zealand Intensive Care Society (ANZICS)'s Centre for Outcome and Resource Evaluation examined temporal mortality trends. In a study involving $>100,000$ sepsis patients, using the same criteria for definition from 2000 to 2012, hospital mortality decreased from 35\% to $18.4 \%{ }^{4}$. After adjustment of illness severity, the odds ratio for mortality had decreased to 0.49 (95\% CI 0.46-0.52) over a little more than a decade.

A recently reported meta-analysis 3723 patients enrolled in three international trials of early goal directed therapy in patients with septic shock reported an overall mortality rate of $25 \%$ at 90 days ${ }^{36}$. Evidence suggests that survivors of sepsis also have significantly higher long-term mortality rates compared to the general population ${ }^{37}$.

\section{Morbidity}

The morbidity associated with sepsis, especially if severe enough to warrant ICU admission is marked and affects all organ systems. This appears to be a growing problem as more elderly or immunocompromised patients or patients with serious chronic co-morbidities are treated for sepsis. This has resulted in a progressive increase in the number of ICU patients, who after surviving the acute event cannot be discharged directly to their home. For example, in the period from 2000 to 2012, the odds for death halved and the annual increase in in discharge home was significantly greater among those with sepsis than nonsepsis patients. However, the odds for being discharged to a rehabilitation

This article is protected by copyright. All rights reserved. 
facility also increased three-fold ${ }^{4}$, Long-term follow up of patients enrolled in two large multicentre sepsis trials found one third of survivors had not returned to independent living at 6 months ${ }^{38}$. This has been related to the loss of function that patient experience after a critical illness whether due to sepsis or another condition and to the so-called post-ICU syndrome ${ }^{39}$.

\section{Post ICU syndrome}

Patients admitted to ICU because of sepsis, experience major loss of muscle mass, muscle strength, hemodynamic and respiratory reserve, renal function, psychological strength and neurocognitive performance, especially if their stay in ICU is prolonged ${ }^{40-42}$. Although not directly relevant to the Emergency Physician, an understanding that sepsis requiring ICU admission can be a dramatic life-changing illness is important for family conversations, perspective and expectations.

\section{Unanswered questions and future directions}

Sepsis-3 reflects our current approach to the definition of sepsis, but further work is needed to develop a practical working definition for ED. This is important in order to undertake research relevant to ED patients and to ED clinicians. Accurately distinguishing sepsis from uncomplicated infection is a key role of the ED, and is essential to balance optimal patient outcomes with resource stewardship. The role of sepsis pathways, along with time-based treatment targets in improving timely recognition of sepsis remains an area of ongoing enquiry. Finally, there is a need for relevant patient-orientated outcome measures, reflecting the increasing incidence of sepsis among the frail and elderly in our community.

Word count 2469

This article is protected by copyright. All rights reserved. 


\section{REFERENCES}

1. Funk DJ, Parrillo JE, Kumar A. Sepsis and septic shock: a history. Crit Care Clin 2009;25:83-101

2. Suarez De La Rica A, Gilsanz F, Maseda E. Epidemiologic trends of sepsis in western countries. Ann Transl Med 2016;4:325.

3. Finfer S, Bellomo R, Lipman J, French C, Dobb G, Myburgh J. Adult-population incidence of severe sepsis in Australian and New Zealand intensive care units. Intensive Care Med 2004;30:589-96.

4. Kaukonen KM, Bailey M, Suzuki S, Pilcher D, Bellomo R. Mortality related to severe sepsis and septic shock among critically ill patients in Australia and New Zealand, 2000-2012. Jama 2014;311:1308-16.

5. Williams JM, Greenslade JH, Dymond CA, Chu K, Brown AF, Lipman J. Characteristics, treatment and outcomes for all emergency department patients fulfilling criteria for septic shock: a prospective observational study. Eur J Emerg Med 2016.

6. Wang HE, Addis DR, Donnelly JP, et al. Discharge diagnoses versus medical record review in the identification of community-acquired sepsis. Crit Care 2015;19:42.

7. Deis A, Whiles B, Miller P, Simpson S. Diagnosis code vs clinical criteria: variable outcomes in patients with severe sepsis and septic shock. Chest 2016;149:A187.

8. Ibrahim I, Jacobs IG, Webb SA, Finn J. Accuracy of International classification of diseases, 10th revision codes for identifying severe sepsis in patients admitted from the emergency department. Crit Care Resusc 2012;14:112-8.

9. Gaieski DF, Edwards JM, Kallan MJ, Carr BG. Benchmarking the incidence and mortality of severe sepsis in the United States. Crit Care Med 2013;41:1167-74.

10. Bone RC, Fisher CJ, Jr., Clemmer TP, Slotman GJ, Metz CA, Balk RA. Sepsis syndrome: a valid clinical entity. Methylprednisolone Severe Sepsis Study Group. Crit Care Med 1989;17:389-93.

11. American College of Chest Physicians/Society of Critical Care Medicine Consensus Conference: definitions for sepsis and organ failure and guidelines for the use of innovative therapies in sepsis. Crit Care Med 1992;20:864-74.

12. Levy MM, Fink MP, Marshall JC, et al. 2001 SCCM/ESICM/ACCP/ATS/SIS International Sepsis Definitions Conference. Intensive Care Med 2003;29:530-8.

13. Kaukonen KM, Bailey M, Pilcher D, Cooper DJ, Bellomo R. Systemic inflammatory response syndrome criteria in defining severe sepsis. N Engl J Med 2015;372:1629-38.

14. Singer M, Deutschman CS, Seymour CW, et al. The Third International Consensus Definitions for Sepsis and Septic Shock (Sepsis-3). JAMA 2016;315:801-10.

15. Vincent JL, de Mendonca A, Cantraine F, et al. Use of the SOFA score to assess the incidence of organ dysfunction/failure in intensive care units: results of a multicenter, prospective study. Working group on "sepsis-related problems" of the European Society of Intensive Care Medicine. Crit Care Med 1998;26:1793-800.

16. Shetty AL, Brown T, Booth T, et al. Systemic inflammatory response syndromebased severe sepsis screening algorithms in emergency department patients with suspected sepsis. Emerg Med Australas 2016;28:287-94.

17. Williams JM, Greenslade JH, McKenzie JV, Chu K, Brown AF, Lipman J. Systemic Inflammatory Response Syndrome, Quick Sequential Organ Function Assessment, and Organ Dysfunction: Insights From a Prospective Database of ED Patients With Infection. Chest 2017;151:586-96. 
18. Turnidge J. Antimicrobial use and resistance in Australia. Aust Prescr 2017;40:2-

3.

19. Rhodes A, Evans LE, Alhazzani W, et al. Surviving Sepsis Campaign: International Guidelines for Management of Sepsis and Septic Shock: 2016. Intensive Care Med 2017;43:304-77.

20. Gotmaker R, Peake SL, Forbes A, Bellomo R, Investigators A. Mortality is Greater in Septic Patients with Hyperlactatemia Than with Refractory Hypotension. Shock 2017.

21. Seymour CW, Liu VX, Iwashyna TJ, et al. Assessment of Clinical Criteria for Sepsis: For the Third International Consensus Definitions for Sepsis and Septic Shock (Sepsis-3). JAMA 2016;315:762-74.

22. Churpek MM, Snyder A, Han X, et al. Quick Sepsis-related Organ Failure Assessment, Systemic Inflammatory Response Syndrome, and Early Warning Scores for Detecting Clinical Deterioration in Infected Patients outside the Intensive Care Unit. American journal of respiratory and critical care medicine 2017;195:906-11.

23. Giamarellos-Bourboulis EJ, Tsaganos T, Tsangaris I, et al. Validation of the new Sepsis-3 definitions: proposal for improvement in early risk identification. Clin Microbiol Infect 2017;23:104-9.

24. Machado FR, Nsutebu E, AbDulaziz S, et al. Sepsis 3 from the perspective of clinicians and quality improvement initiatives. J Crit Care 2017.

25. Charles PG, Wolfe R, Whitby M, et al. SMART-COP: a tool for predicting the need for intensive respiratory or vasopressor support in community-acquired pneumonia. Clin Infect Dis 2008;47:375-84.

26. Buising KL, Thursky KA, Black JF, et al. Identifying severe community-acquired pneumonia in the emergency department: a simple clinical prediction tool. Emerg Med Australas 2007;19:418-26.

27. Knaus WA, Wagner DP, Draper EA, et al. The APACHE III prognostic system. Risk prediction of hospital mortality for critically ill hospitalized adults. Chest 1991;100:1619-36.

28. Shapiro NI, Wolfe RE, Moore RB, Smith E, Burdick E, Bates DW. Mortality in Emergency Department Sepsis (MEDS) score: a prospectively derived and validated clinical prediction rule. Crit Care Med 2003;31:670-5.

29. Williams JM, Greenslade JH, Chu K, Brown AF, Lipman J. Severity Scores in Emergency Department Patients With Presumed Infection: A Prospective Validation Study. Crit Care Med 2016;44:539-47.

30. Rubulotta F, Marshall JC, Ramsay G, Nelson D, Levy M, Williams M. Predisposition, insult/infection, response, and organ dysfunction: A new model for staging severe sepsis. Crit Care Med 2009;37:1329-35.

31. Howell MD, Talmor D, Schuetz P, Hunziker S, Jones AE, Shapiro NI. Proof of principle: the predisposition, infection, response, organ failure sepsis staging system. Crit Care Med 2011;39:322-7.

32. Macdonald SP, Arendts G, Fatovich DM, Brown SG. Comparison of PIRO, SOFA, and MEDS scores for predicting mortality in emergency department patients with severe sepsis and septic shock. Acad Emerg Med 2014;21:1257-63.

33. Gultepe E, Green JP, Nguyen H, Adams J, Albertson T, Tagkopoulos I. From vital signs to clinical outcomes for patients with sepsis: a machine learning basis for a clinical decision support system. J Am Med Inform Assoc 2014;21:315-25. 
34. Epstein L, Dantes R, Magill S, Fiore A. Varying Estimates of Sepsis Mortality Using Death Certificates and Administrative Codes - United States, 1999-2014. MMWR

Morbidity and mortality weekly report 2016;65:342-5.

35. Fleischmann C, Scherag A, Adhikari NK, et al. Assessment of Global Incidence and Mortality of Hospital-treated Sepsis. Current Estimates and Limitations. American journal of respiratory and critical care medicine 2016;193:259-72.

36. PRISM Investigators, Early, Goal-Directed Therapy for Septic Shock - A PatientLevel Meta-Analysis. N Engl J Med 2017;376:2223-34.

37. Kaur A, Levy MM. Role of sepsis in delayed mortality. Ann Transl Med 2016;4:378.

38. Yende S, Austin S, Rhodes A, et al. Long-Term Quality of Life Among Survivors of Severe Sepsis: Analyses of Two International Trials. Crit Care Med 2016;44:1461-7. 39. Jensen JF, Thomsen T, Overgaard D, Bestle MH, Christensen D, Egerod I. Impact of follow-up consultations for ICU survivors on post-ICU syndrome: a systematic review and meta-analysis. Intensive Care Med 2015;41:763-75.

40. Iwashyna TJ, Hodgson CL, Pilcher D, Bailey M, Bellomo R. Persistent critical illness characterised by Australian and New Zealand ICU clinicians. Critical care and resuscitation : journal of the Australasian Academy of Critical Care Medicine 2015;17:153-8.

41. Iwashyna TJ, Hodgson CL, Pilcher D, et al. Towards defining persistent critical illness and other varieties of chronic critical illness. Critical care and resuscitation : journal of the Australasian Academy of Critical Care Medicine 2015;17:215-8.

42. Hodgson CL, Udy AA, Bailey M, et al. The impact of disability in survivors of critical illness. Intensive Care Med 2017;43:992-1001. 


\section{Figure Legend}

Figure 1: Schematic representation of Sepsis-1 and Sepsis-3 subgroups. Each box indicates a population of ED patients with infection. Panel A: Sepsis-2 subgroups of sepsis, severe sepsis and septic shock. SIRS = systemic inflammatory response syndrome. Patients with organ dysfunction or shock but without SIRS are not included, despite similar mortality to those with SIRS. Panel B: Sepsis-3 subgroups of sepsis and septic shock. SIRS plays no role, depite being associated with greater risk of organ dysfunction in ED patients with infection, and mortality in those without organ dysfunction (17).

This article is protected by copyright. All rights reserved. 


\begin{tabular}{|c|c|c|c|c|c|c|}
\hline SYSTEM & SCORE & $\mathbf{0}$ & 1 & 2 & 3 & 4 \\
\hline RESPIRATORY & $\begin{array}{l}\mathrm{PaO}_{2} / \mathrm{FiO}_{2} \\
\mathrm{SpO}_{2} / \mathrm{FiO}_{2} \\
\mathrm{SpO}_{2}\end{array}$ & $\begin{array}{l}>400 \\
>400 \\
>94 \% \text { (RA) } \\
\pm \text { respiratory support }\end{array}$ & $\begin{array}{l}<400 \\
<400 \\
\geq 90 \% \text { on 6lpm } \\
\pm \text { respiratory support }\end{array}$ & $\begin{array}{l}<300 \\
<315 \\
<90 \% \text { on }>6 \text { lpm } \\
\pm \text { respiratory suppor }\end{array}$ & $\begin{array}{l}<200 \\
<235 \\
+ \text { respiratory support }\end{array}$ & $\begin{array}{l}100 \\
<150 \\
+ \text { respiratory support }\end{array}$ \\
\hline $\begin{array}{l}\text { CARDIO } \\
\text {-VASCULAR }\end{array}$ & 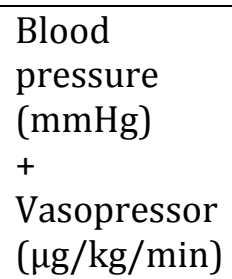 & $\begin{array}{l}\mathrm{SBP}>90 \\
\text { at all times }\end{array}$ & $\begin{array}{l}\text { SBP }>90 \\
\text { after fluid } \\
\text { bolus } 20 \mathrm{ml} / \mathrm{kg}\end{array}$ & $\begin{array}{l}\text { SBP }<90 \mathrm{mmHg} \\
\text { despite fluid } \\
\text { bolus } \\
\text { Dopamine } \leq 5 \\
\text { Dobutamine }\end{array}$ & $\begin{array}{l}\text { Dopamine }>5 \\
\text { Noradrenaline } \leq 0.1\end{array}$ & $\begin{array}{l}\text { Dopamine }>15 \\
\text { Noradrenaline }>0.1\end{array}$ \\
\hline HAEMATOLGY & $\begin{array}{l}\text { Platelets } \\
\text { (x109/L) }\end{array}$ & $>150$ & $100-150$ & $50-99$ & $20-49$ & $<20$ \\
\hline $\begin{array}{l}\text { GASTRO } \\
\text {-INTESTINAL }\end{array}$ & $\begin{array}{l}\text { Bilirubin } \\
(\mu \mathrm{mol} / \mathrm{L})\end{array}$ & $<20$ & $20-32$ & $33-101$ & $102-204$ & $>204$ \\
\hline
\end{tabular}




\begin{tabular}{|c|c|c|c|c|c|c|}
\hline RENAL & $\begin{array}{l}\text { Creatinine } \\
(\mu \mathrm{mol} / \mathrm{L}) \\
\text { OR } \\
\text { urine output } \\
(\mathrm{ml} / \mathrm{kg} / \mathrm{hr})\end{array}$ & $<110$ & $\begin{array}{l}>110-170 \\
<0.5 \text { for } \\
2 \text { hours }\end{array}$ & $>171-300$ & $301-440$ & $>440$ \\
\hline
\end{tabular}

Table 1 Sequential Organ Failure Assessment (SOFA) score (15), with modification of respiratory component to include FiO $\mathrm{CSpO}_{2}$ or supplemental oxygen where the $\mathrm{pAO}_{2}$ is not measured or patient is not ventilated (Pandharipande et al, Crit Care Med 2009;37:1317-

21). 


\begin{tabular}{|l|c|}
\hline Variable & Score \\
Terminal illness & 6 \\
\cline { 2 - 2 } Age $>65$ years & 3 \\
Shockypnoea or hypoxia & 3 \\
Platelets $<150 \times 10^{9} / \mathrm{L}$ & 3 \\
Altered mental state & 2 \\
Nursing home resident & 2 \\
\hline Lower respiratory infection & 2 \\
\hline \multicolumn{1}{|c|}{ MAXIMUM SCORE if all variables present } & 24 \\
\hline
\end{tabular}

Table 2 Mortality in ED Sepsis (MEDS) score (28), excluding neutrophil bands $>5 \%$ giving maximal total score of 24, as described by Vorwerk et al, Emerg Med J, 2009;26:254-8. 


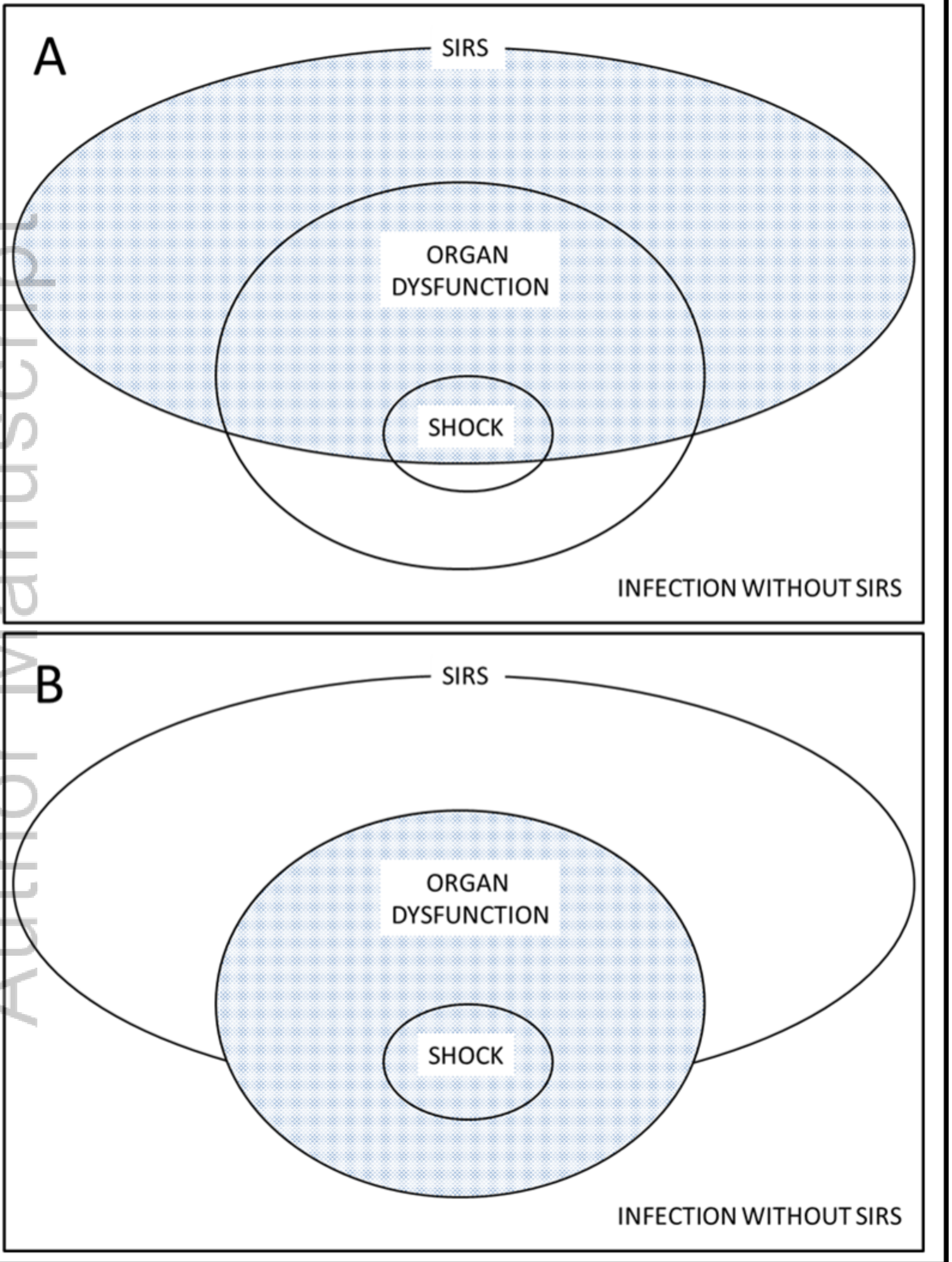

This article is protected by congycigett. Alf rights reserved. 


\section{University Library}

\section{- M M N E R VA A gateway to Melbourne's research publications}

Minerva Access is the Institutional Repository of The University of Melbourne

Author/s:

Macdonald, SPJ;Williams, JM;Shetty, A;Bellomo, R;Finfer, S;Shapiro, N;Keijzers, G

Title:

Review article: Sepsis in the emergency department - Part 1: Definitions and outcomes

Date:

2017-12-01

Citation:

Macdonald, S. P. J., Williams, J. M., Shetty, A., Bellomo, R., Finfer, S., Shapiro, N. \&

Keijzers, G. (2017). Review article: Sepsis in the emergency department - Part 1: Definitions and outcomes. EMERGENCY MEDICINE AUSTRALASIA, 29 (6), pp.619-625. https:// doi.org/10.1111/1742-6723.12886.

Persistent Link:

http://hdl.handle.net/11343/293814 